\title{
Free daily newspapers: too strong incentives to print?
}

\author{
João Correia-da-Silva $\cdot$ Joana Resende
}

Received: 24 June 2012 / Accepted: 14 March 2013 / Published online: 20 April 2013

(C) ISEG 2013

\begin{abstract}
A free daily newspaper distributes news to readers and sells ad-space to advertisers, having private information about its audience. For a given number of distributed copies, depending on the type of audience (favorable or unfavorable), the newspaper may either have a large readership or a small readership. A large readership provides a greater return to advertisers, because ads are visualized by more people. A favorable audience has also the advantage of requiring a lower distribution cost (for a given number of distributed copies), because readers are willing to exert more effort to obtain a copy of the free newspaper and are less likely to reject a copy that is handed to them. We find that when the audience is unfavorable, the number of distributed copies and the price of ad-space coincide with those of the perfect information scenario. In contrast, if the audience is favorable, the newspaper prints extra copies to send a credible signal to the advertisers that the audience is favorable. Overprinting is not necessarily welfare-detrimental since readers benefit from the existence of additional copies.
\end{abstract}

Keywords Asymmetric information · Two-sided markets · Free press

JEL Classification D82 - D86 $\cdot$ L82

\footnotetext{
We thank Jean Gabszewicz, Paolo Garella, Didier Laussel, Inés Macho-Stadler, Frank Page, and the participants in the Doctoral Workshop of the Université catolique de Louvain (2008/2009), the 2009 SAET Conference in Ischia and the 3rd Economic Theory Workshop in Vigo. We also thank two anonymous referees and Odd-Rune Straume (Editor) for their useful comments and suggestions. João Correia-da-Silva (joao@fep.up.pt) and Joana Resende (jresende@fep.up.pt) acknowledge financial support from CEF.UP and from Fundação para a Ciência e Tecnologia and FEDER (PTDC/EGE-ECO/111811/2009).

J. Correia-da-Silva $\cdot$ J. Resende

CEF.UP and Faculdade de Economia, Universidade do Porto, Rua Dr. Roberto Frias, 4200-464 Porto, Portugal

e-mail: jresende@fep.up.pt

J. Correia-da-Silva

e-mail: joao@fep.up.pt
} 